\title{
TINGKAT PENDIDIKAN DAN TINGKAT KECEMASAN PADA KLIEN PENDERITA DIABETES MELITUS DI POLIKLINIK RSUD CIAMIS
}

\author{
${ }^{1}$ Jajuk Kusumawaty, ${ }^{2}$ Lilis Lismayanti, \& ${ }^{3}$ Pipin Fitria \\ $1,2,3$ Prodi Ners STIKes Muhammadiyah Ciamis.
}

jajuk09@yahoo.com

\begin{abstract}
Abstrak
Penyakit diabetes mellitus merupakan penyakit kronis yang mempunyai dampak negatif terhadap fisik maupun psikologis. Dampak psikologis yang terjadi yaitu kecemasan yang merupakan gangguan mental emosional. Biasanya respon terhadap kenyataan, ancaman kehilangan dan kesakitan dalam bentuk manifestasi suasana cemas berkepanjangan yang, menetap atau timbul sewaktu-waktu, timbul pula gambaran diri yang buruk dan merasa kehilangan harapan. Tujuan penelitian ini untuk mengetahui gambaran tingkat pendidikan dan tingkat kecemasan pada klien yang menderita diabetes mellitus. Desain penelitian menggunakan desain deskriptif kuantitatif. Populasi dalam penelitian ini adalah semua klien diabetes mellitus yang datang ke Poliklinik RSUD Ciamis periode 18 - 23 Mei 2015. Teknik sampling menggunakan total populasi sebanyak 30 responden. Hasil penelitian menunjukan bahwa tingkat pendidikan klien penderita diabetes mellitus sebagian besar berpendidikan dasar (SD - SMP) sebanyak 14 orang $(46,7 \%)$, dan tingkat kecemasan klien penderita diabetes mellitus sebagian besar pada kecemasan sedang sebanyak 13 orang $(43,3 \%)$. Pendidikan merupakan salah satu faktor yang dapat mempengaruhi seseorang dalam berperilaku. Pendidikan yang kurang akan menghambat perkembangan sikap seseorang terhadap nilai-nilai yang baru diketahuinya.
\end{abstract}

Kata Kunci : Diabetes Mellitus, Pendidikan, Kecemasan

\begin{abstract}
Diabetes mellitus is a chronic disease that has a negative impact on physical and psychological. The psychological impact that occurs is anxiety that is an emotional mental disorder. Usually the response to the fact, the threat of loss and pain in the form of manifestations of anxious, prolonged, persistent or occurring moments, also emerges of poor self-image and loss of hope. The purpose of this study to determine the picture level of education and anxiety levels in clients who suffer from diabetes mellitus. The research design uses a quantitative descriptive design. The population in this study were all clients of diabetes mellitus who came to the Polyclinic RSUD Ciamis period 18 to 23 May 2015. Sampling technique using the total population of 30 respondents. The results showed that the education level of clients with diabetes mellitus was mostly elementary school (SD - SMP) as many as 14 people (46,7\%), and the anxiety level of clients with diabetes mellitus mostly on the anxiety was 13 people (43,3\%). Education is one factor that can affect a person in behaving. Less education will hamper the development of one's attitude toward new values.
\end{abstract}

Keywords: Diabetes Mellitus, Education, Anxiety

\section{PENDAHULUAN}

Diabetes melitus merupakan gangguan metabolisme yang secara genetis dan klinis termasuk heterogen dengan manifestasi berupa hilangnya toleransi karbohidrat. Diabetes mellitus ditandai dengan hiperglikemia puasa dan postprandial, penyakit vaskular mikroangiopati, dan neuropati. Pasien dengan kelainan intoleransi glukosa ringan (gangguan glukosa puasa dan gangguan intoleransi glukosa) dapat tetap beresiko 
mengalami komplikasi metabolik diabetes. Penderita diabetes mellitus $75 \%$ meninggal karena penyakit vaskuler, serangan jantung, gagal ginjal, stroke, dan ganggren adalah komplikasi utama. Dampak ekonomi pada diabetes melitus terlihat dari biaya pengobatan dan hilangnya pendapatan, selain konsekuensi finansial karena banyaknya komplikasi seperti kebutaan dan penyakit vaskuler (Price, 2012).

Berdasarkan survey WHO (dalam Sumarno, 2012) diketahui bahwa jumlah penderita diabetes melitus di Indonesia mencapai sekitar 17 juta orang (8,6 persen dari jumlah penduduk). Terjadi peningkatan prevalensi diabetes melitus di Indonesia dari 1,1\% (2007) menjadi 2,1\% (2013). Angka kesakitan dan kematian akibat diabetes melitus di Indonesia cenderung berfluktuasi setiap tahunnya sejalan dengan perubahan gaya hidup masyarakat yang mengarah pada makanan siap saji dan sarat karbohidrat (Kemenkes, 2013). Penyakit diabetes melitus merupakan masalah kesehatan masyarakat yang serius. Jumlah pasien rawat inap maupun rawat jalan di rumah sakit menempati urutan pertama dari seluruh penyakit endokrin adalah diabetes melitus (Tandra, 2011).

Propinsi Jawa Barat menduduki peringkat 11 untuk kasus diabetes mellitus dengan prevalansi yang terdiagnosis dokter $1,3 \%$ dan prevalensi diabetes melitus yang terdiagnosis dokter atau gejala 2,0\% (Kemenkes, 2013). Berdasarkan profil kesehatan propinsi Jawa Barat tahun 2013, proporsi penderita diabetes melitus menurut umur 15-44 tahun terdapat 3,6\% dan > 45 tahun terdapat $96,4 \%$ kondisi tersebut terjadi merata di seluruh Kabupaten/Kota di Jawa Barat. Peningkatan kasus diabetes melitus tersebut dikarenakan peningkatan pendapatan dan perubahan gaya hidup masyarakat (Dinkes Jabar, 2013).

Penyakit diabetes mellitus merupakan suatu penyakit kronis yang mempunyai dampak negatif terhadap fisik maupun psikologis penderita, gangguan fisik yang terjadi seperti poliuria, polidipsia, polifagia, mengeluh lelah dan mengantuk, disamping itu dapat mengalami penglihatan kabur, kelemahan dan sakit kepala (Price \&Wilson, 2006). Dampak psikologis yang terjadi seperti kecemasan, kemarahan, berduka, malu, rasa bersalah, hilang harapan, depresi, kesepian, tidak berdaya, juga dapat menjadi pasif, tergantung, merasa tidak nyaman, bingung dan merasa menderita (Purwaningsih \& Karlina, 2012). Menurut Mapierre dalam Rahmi (2010), terdapat berbagai faktor yang berhubungan dengan tingkat kecemasan seseorang, beberapa diantaranyayaitu usia, tingkat pendidikan, dan dukungan keluarga.

Hasil penelitian yang dilakukan oleh Yusra (2010) menunjukkan bahwa tingkat pendidikan memiliki hubungan dengan kualitas hidup. Selain itu penelitian yang dilakukan oleh Wahyuni (2013) menunjukkan bahwa semakin tinggi tingkat pendidikan seseorang maka semakin tinggi kualitas hidupnya.

\section{METODE PENELITIAN}

Desain penelitian menggunakan desain penelitian deskriptif kuantitatif. Populasi dalam penelitian ini adalah semua klien diabetes mellitus yang datang ke Poliklinik RSUD Ciamis periode $18-23$ Mei 2015. Teknik sampling menggunakan total populasi sebanyak 30 responden.

Data yang digunakan dalam penelitian ini menggunakan data primer yaitu data yang langsung diperoleh dari objek penelitian yang dilakukan dengan cara membagikan angket kepada responden. Instrument penelitian untuk mengukur kecemasan menggunakan metode HARS (Hamilton Anxiety Rating Scale). Metode pengolahan data terdiri dari pemeriksaan data (editing data), pemberian kode (coding), pemasukan data (entry data) dan pembersihan data (cleaning data). Analisis data dilakukan untuk mengetahui distribusi 
frekuensi dari variable pendidikan dan kecemasan.

\section{HASIL PENELITIAN}

Gambaran Tingkat Pendidikan Klien Penderita Diabetes Mellitus di Poliklinik Rumah Sakit Umum Daerah Kabupaten Ciamis.

Tabel 1. Distribusi Frekuensi Tingkat

Pendidikan Klien Penderita Diabetes Mellitus

\begin{tabular}{llcc}
\hline Pendidikan & F & $\begin{array}{c}\text { Persentasi } \\
(\%)\end{array}$ \\
\hline 1. & SD - SMP & 14 & 46,6 \\
2. & SMA & 11 & 36,7 \\
3. & PT & 5 & 16,7 \\
\hline \multicolumn{2}{l}{ Jumlah } & 30 & 100 \\
\hline
\end{tabular}

Berdasarkan tabel 1. diketahui bahwa pendidikan klien yang menderita diabetes mellitus di Poliklinik Rumah Sakit Umum Daerah Kabupaten Ciamis, frekuensi tertinggi yaitu berkategori pendidikan dasar (SD-SMP) sebanyak 14 orang $(46,6 \%)$, pendidikan menengah (SMA) sebanyak 11 orang $(36,7 \%)$ dan frekuensi terendah yaitu kategori pendidikan tinggi (PT) sebanyak 5 orang $(16,7 \%)$.

Gambaran Tingkat Kecemasan Klien Penderita Diabetes Mellitus di Poliklinik Rumah Sakit Umum Daerah Kabupaten Ciamis.

Tabel 2. Distribusi Frekuensi Tingkat Kecemasan Klien Penderita Diabetes Mellitus

\begin{tabular}{llcc}
\hline $\begin{array}{c}\text { Tingkat } \\
\text { Kecemasan }\end{array}$ & F & $\begin{array}{c}\text { Persentasi } \\
(\%)\end{array}$ \\
\hline 1. & Tidak Cemas & 4 & 13,3 \\
2. & Cemas Ringan & 9 & 30 \\
3. Cemas Sedang & 13 & 43,4 \\
4. & Cemas Berat & 4 & 13,3 \\
\hline & Jumlah & 30 & 100 \\
\hline
\end{tabular}

Pada tabel 2. menunjukkan bahwa tingkat kecemasan klien yang menderita diabetes mellitus di Poliklinik Rumah Sakit Umum Daerah Kabupaten Ciamis, frekuensi tertinggi yaitu memiliki kecemasan sedang sebanyak 13 orang $(43,4 \%)$, dan frekuensi terendah yaitu memiliki kecemasan berat dan tidak ada kecemasan masing-masing sebanyak 4 orang $(13,3 \%)$.

\section{PEMBAHASAN}

Hasil penelitian menunjukan bahwa tingkat pendidikan klien yang menderita diabetes mellitus di Poliklinik Rumah Sakit Umum Daerah Kabupaten Ciamis sebagian besar berkategori pendidikan dasar (SD-SMP) sebanyak 14 orang (46,7\%). Tingkat pendidikan akan menentukan mudah atau tidaknya seseorang dalam menyerap dan memahami pengetahuan yang mereka peroleh, pada umumnya semakin tinggi pendidikan seseorang makin baik pula pengetahuannya, sehingga dengan mudahnya penerimaan terhadap informasi terkait kesehatan tentunya akan memudahkan pasien diabetes melitus dalam melaksanakan manajemen perawatan diabetes melitus yang akan meningkatkan kualitas hidupnya pasien diabetes mellitus.

Menurut Notoatmodjo (2012) pendidikan merupakan salah satu faktor yang dapat mempengaruhi seseorang dalam berperilaku. Makin tinggi tingkat pendidikan seseorang, semakin tinggi pula pemahaman dan daya tangkap terhadap materi atau informasi sehingga semakin banyak pula pengetahuan yang dimilikinya. Sebaliknya, pendidikan yang kurang akan menghambat perkembangan sikap seseorang terhadap nilai-nilai yang baru diketahuinya.

Hasil penelitian yang dilakukan oleh Yusra (2010), menunjukkan bahwa tingkat pendidikan memiliki hubungan dengan kualitas hidup. Penelitian yang dilakukan oleh Wahyuni (2013) juga menunjukkan bahwa semakin tinggi tingkat pendidikan 
seseorang maka semakin tinggi kualitas hidupnya.

Hasil penelitian menunjukan bahwa tingkat kecemasan pada klien yang menderita diabetes mellitus di Poliklinik RSUD Ciamis, frekuensi tertinggi yaitu memiliki kecemasan sedang sebanyak 13 orang $(43,3 \%)$, dan frekuensi terendah yaitu kategori kecemasan berat dan tidak ada kecemasan masing-masing sebanyak 4 orang (13,3\%). Hal tersebut mengindikasikan bahwa tingkat kecemasan penderita diabetes mellitus sangat beragam. Penderita diabetes mellitus yang mengalami kecemasan sedang hingga berat kemungkinan disebabkan oleh kurangnya pengetahuan tentang komplikasi diabetes mellitus dan cara pencegahanya. Sebagian besar penderita pasien penyakit kronik mengalami kecemasan akibat beberapa komplikasi yang mengiringi perjalanan penyakitnya.

Penderita diabetes mellitus yang mengalami kecemasan ringan kemungkinan disebabkan karena sudah terpapar pengetahuan tentang diabetes mellitus. Penderita diabetes mellitus yang mengalami kecemasan ringan mempunyai riwayat keluarga diabetes mellitus dan sudah lama terdiagnosa menderita diabetes mellitus. Beberapa penderita diabetes mellitus juga ada yang tidak mengalami kecemasan, hal tersebut kemungkinan disebabkan karena tingkat pengetahuannya tentang pencegahan komplikasi diabetes mellitus sudah baik.

Menurut Stuart (2007) kecemasan adalah kekhawatiran yang tidak jelas dan menyebar, yang berkaitan dengan perasaan tidak pasti dan tidak berdaya, dan keadaan emosi ini tidak memiliki objek yang spesifik. Kecemasan ringan berhubungan dengan ketegangan dalam kehidupan sehari-hari, ansietas ini menyebabkan individu menjadi waspada dan meningkatkan lapang persepsinya. Kecemasan sedang memungkinkan individu untuk berfokus pada hal yang penting dan mengesampingkan yang lain.
Ansietas ini mempersempit lapang persepsi individu. Individu mengalami tindak perhatian yang tidak selektif namun dapat berfokus pada lebih banyak area jika diarahkan untuk melakukannya. Kecemasan berat sangat mengurangi lapang persepsi individu. Individu cenderung berfokus pada sesuatu yang rinci dan spesifik serta tidak berpikir tentang hal lain. Semua perilaku ditujukan untuk mengurangi ketegangan. Individu tersebut memerlukan banyak arahan untuk pada area lain.

Hasil penelitian ini sesuai dengan yang dilakukan Handayani (2014) tentang hubungan pelaksanaan tugas kesehatan keluarga dengan tingkat kecemasan penderita diabetes melitus Tipe 2 (NIDDM) Di Poli Dalam RSUD dr. R. Goeteng Taroenadibrata Purbalingga yang menyatakan sebagian besar responden mengalami kecemasan pada tahap ringan dan hanya sedikit diantaranya yang tidak mengalami kecemasan sama sekali dan kecemasan berat.

Kecemasan pasien terhadap segala hal yang berhubungan dengan diabetesnya, misalnya cemas terhadap kadar gula yang tinggi, cemas terhadap komplikasi akibat diabetes, dan sebagainya. Penyakit diabetes mellitus merupakan suatu penyakit kronis yang mempunyai dampak negatif terhadap fisik maupun psikologis penderita, gangguan fisik yang terjadi seperti poliuria, polidipsia, polifagia, mengeluh lelah dan mengantuk, disamping itu dapat mengalami penglihatan kabur, kelemahan dan sakit kepala (Price \& Wilson, 2006). Dampak psikologis yang terjadi seperti kecemasan, kemarahan, berduka, malu, rasa bersalah, hilang harapan, depresi, kesepian, tidak berdaya, juga dapat menjadi pasif, tergantung, merasa tidak nyaman, bingung dan merasa menderita (Purwaningsih \& Karlina, 2012). Sebagaimana firman Alloh SWT dalam surat Ali Imran 3 Ayat 139, yang artinya: "Janganlah kamu bersikap lemah (pesimis), dan janganlah (pula) kamu bersedih hati, padahal kamu adalah 
orang-orang yang paling tinggi (derajatnya), jika kamu orang-orang yang beriman". (Ali-Imran 3 : 139).

Sikap optimis haruslah mengalahkan pesimis yang bisa jadi menyelinap dalam hati, untuk itulah jika ingin hidup sukses, maka harus bisa membangun rasa optimis dalam diri. Pasien diabetes mellitus harus mampu untuk percaya bahwa hidup memang tidak mudah, tetapi dengan upaya baru, hidup akan menjadi lebih baik. Upaya yang dapat dilakukan oleh penderita dibetes mellitus adalah dengan pengobatan ataupun dengan melakukan pola hidup yang sehat. Seperti hadist yang riwayatkan Imam Muslim dari Jabir bin Abdillah dia berkata bahwa Nabi bersabda, "Setiap penyakit pasti memiliki obat. Bila sebuah obat sesuai dengan penyakitnya maka dia akan sembuh dengan seizin Allah Subhanahu wa Ta'ala" (HR. Muslim).

Hadist di atas memberikan pengertian kepada kita bahwa semua penyakit yang menimpa manusia maka Allah turunkan obatnya. Kadang ada orang yang menemukan obatnya, ada juga orang yang belum bisa menemukannya. Oleh karenanya seseorang harus bersabar untuk selalu berobat dan terus berusaha untuk mencari obat ketika sakit sedang menimpanya.

\section{KESIMPULAN}

Sebagian besar klien penderita diabetes mellitus berkategori pendidikan dasar (SD-SMP) sebanyak 14 orang $(46,7 \%)$, dan kecemasan pada klien penderita diabetes mellitus frekuensi tertinggi berkategori kecemasan sedang sebanyak 13 orang $(43,3 \%)$, kecemasan ringan sebanyak 9 orang $(30 \%)$ dan frekuensi terendah yaitu kategori kecemasan berat dan tidak ada kecemasan masing-masing sebanyak 4 orang $(13,3 \%)$.

\section{SARAN}

Lakukan upaya dengan pengobatan dan melakukan pola hidup yang sehat. Peneliti selanjutnya agar melakukan penelitian lebih lanjut tentang faktor-faktor yang memengaruhi kecemasan pada klien diabetes melitus.

\section{DAFTAR PUSTAKA}

Al Quran

Al Hadist

Dinkes Jabar, (2013). Profil Kesehatan Propinsi Jawa Barat 2012, tersedia dalam http://www.dinkesjabar.go.id/ [diakses 10 Maret 2015]

Kemenkes RI., (2013). Riset Kesehatan Dasar 2013. Badan Penelitian Dan

Pengembangan Kesehatan Kementerian Kesehatan RI

Notoatmodjo, S., (2010). Metodologi Penelitian Kesehatan, Rineka Cipta Jakarta.

$$
\text { , (2012). Promosi }
$$

Kesehatan Dan Perilaku Kesehatan Rineka cipta: Jakarta.

Price, 2012 Patologi Konsep Klinis Proses-Proses Penyak it, Edisi ke delapan, EGC: Jakarta.

Price S.A \& Wilson L.M, (2006). Patofisiologi Konsep Klinis dan Proses-Proses Penyak. EGC: Jakarta.

Purwaningsih W., \& Karlia I., (2012). Asuhan Keperawatan Jiwa. Nuha Medika: Yogyakarta.

Rahmi, (2010). Hubungan usia, tingkat pendidikan, dukungan suami, dan dukungan keluarga dengan tingkat kecemasan menjelang persalinan pada ibu primigravida Trimester III Dipoliklinik Kebidanan RSUP dr. M. Djamil Padang Tahun 2009. Penelitian Keperawatan Maternitas. Fakultas Keperawatan Universitas Andalas.

Stuart, G.W., (2007). Buku saku keperawatan jiwa. Ed.5. Jakarta: EGC.

Yusra, (2010). Hubungan Antara Dukungan Keluarga dengan Kualitas Hidup. 